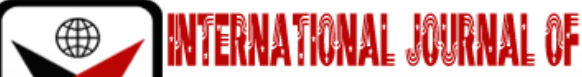

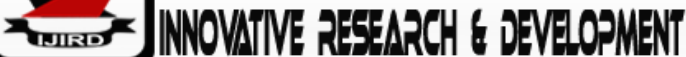

ISSN 2278 - 0211 (Online)

\section{Practice of Social Media Influencing Business Performance of Green Tea Leaves Collectors at the Pitigala Area in Galle District of Sri Lanka}

\begin{tabular}{|c|}
\hline Dr. Sriyani Ranasinghe \\
Senior Lecturer, Department of Entrepreneurship, \\
University of Sri Jayewardenepura, Sri Lanka
\end{tabular}

\begin{abstract}
:
The main objective of this study is to examine the manner in which the Social Media affects the business performance of the Green tea leaves collectors at Pitigala area in Galle district of Sri Lanka. The use of social media for marketing, customer relations and information availability to improve the business performance of Green tea leaves collectors are considered in this study based on literature. A structured questionnaire was distributed among Green tea leaves collectors in the relevant area, where social media is used for their business functions, to obtain data relevant for the study. The results revealed that the use of social media indicates a strong effect on business performance of Green tea leaves collectors in relation to specific areas of customer relations and information accessibility. This research study encompasses a perfect view with regard to the significance of using social media and the accrued benefits to the development of the tea industry in Sri Lanka.
\end{abstract}

Keywords:Social media, customer relations, information accessibility, performance, practice

\section{Introduction}

Social Media can be regarded as an instrument that helps most of the business organizations nowadays to strive in the market. Social media has become a persistent part of daily life today, which is a concept progressed through the development of information technology (Shabbir, Ghazi and Mehmood, 2016). Nevertheless, today, social media has become an online business platform for selling products and services to customer groups (Asur et al., 2011) in addition to connecting people. Therefore, the main objective of this research study is to comprehend the effect of social media on the business performance of Green tea leaves collectors at the Pitigala area in Galle district in Sri Lanka

In the tea Industry in the Sri Lankan economy Green tea leaves collectors are regarded as the problem background. However, many of the Green tea leaves collectors in the region breakdown at the growth stage of the business phase, due to absence of performance in relation to profit and cost reduction (Shabbir, Ghazi and Mehmood, 2016). The key reasons responsible for this disaster can be identified as less adaptability to the variations in the marketplace, poor customer relations, absence of availability to the correct information (FarlexInc, 2018). The Green tea leaves collectors cannot attain peak performance of the businesses due to the nonexistence of adaptation. Currently the major barrier in enhancing the market share of these centers happens to be the fewer use of technology (Fernando et al., 2017). Many organizations make use of the modern tool of social media to compete in the market. It has been acknowledged that the performance and market share of many organizations have been increased due to active engagements in social media. Hence, it helps to removes barriers and increases the performance of these centers in the country. This research study intends to examine the relationship of social media and business performance of Green tea leaves collectors at the Pitigala area in Galle district of Sri Lanka. It is expected to the development of the tea industry of the country.

The research problem that is examined is, "What is the Impact of Practice of the Social Media on Business Performance of Green Tea Leaves Collectors at the Pitigala Area in Galle District of Sri Lanka?" The key objective of the research is to investigate the effect the Practice of Social Media on Business Performance of Green Tea Leaves Collectors at the Pitigala Area in Galle district of Sri Lanka.

\section{Literature Review}

Conventionally, the internet was mainly used for content reading and for trading commitments (Shabbir, Ghazi and Mehmood, 2016). However, the internet has arisen in a rushing proportion, creating it to be a part of our daily life. Today, users of the internet create various platforms for establishment, modification, sharing and discussion of available contents demonstrating the spectacle of social media. Social media has made a revolutionary change in the business empire, as an aspect having an extraordinary influence on the community, 
In relation to the concept of social media, literature discusses few theories (Shabbir, Ghazi and Mehmood, 2016). The media component of the social media is covered in the media research theory, among other theories (Shabbir, Ghazi and Mehmood, 2016). Social presence and media richness sub components are emphasized in this theory. Social Presence theory is concerned about the level of closeness that one can achieve through technology. Social Processes theory is another theory with regard to social media and it specifies the social dimension of Social Media. Self-Presentation and SelfDisclosure sub-theories are included in this theory (Stockdale and Ahmed, 2012). Self-Presentation theory explains the desire of the people to regulate another person's impression that forms in their mind. This represents the concern for having control to get rewards and to form an image that is stable with one's character. Conversely, Self-Disclosure is concerned about releasing personal information deliberately or unintentionally. This can be regarded as vital in making solid relationships (Shaw Atanu, 2018).

\subsection{Concept of Social Media}

Human beings are known to be social creatures by nature, who rely on making relationships and maintaining same. The need for social media platforms which assists or communication were created as a result of this greater dependency on social interactions. Now social media has become a need and it is no longer regarded as a want of the people (Shaw Atanu, 2018). Observing the social media wave in the society, businesses too started to setup suitable social media channels to conquer the competition. Social media replaced the occurrence of the digital technology, the traditional printing and broadcasting activities by taking over the marketing and advertising channels. Within such an infiltration, businesses realize the importance of using social media for commercial activities particularly in the world of marketing.

Social Media tend to cater to serve people who are social creatures and depend more on their ability to interact and inspire their surroundings for survival. People sought to make social networks, in order to broaden the level of social connections that are worldwide. The necessity for a physical reunion was avoided through the expansion of virtual technology, which led to the development of social media sites to have social connections. Social Media can be regarded as a source of user information, which connects people with similar ambitions or desires. The idea Social Media has been advanced over time since its inception. (Edosomwan et al., 2011) highlighting the need for modifying the definition of Social Media. The need for differentiating Social Media from Social Networking and Web 2.0 technology has arisen due to the compatible use of Social Media along with Social Networking and Web 2.0 technology (Stockdale and Ahmed, 2012). The term Social Media is defined as "a group of internet-based applications built on the conceptual and technological foundations of Web 2.0 which allows the formation and interchange of User Generated Content" (Kaplan and Haenlein, 2010). A platform named as Web 2.0 was started from 2004 by the software developers and the users of World Wide Web, where user content and applications are developed, circulated and improved continuously in collaboration with the users which later known as the technological foundation of Social Media. Nevertheless, people use Social Media by summation of user-generated content. Since the beginning of Six degrees which is the first modern Social Media site, people started to start relationships, make friends by messaging and posting items on bulletin board (McFadden, 2017). Six degrees was followed by more Social Media sites such as MySpace, Last FM, LinkedIn, WordPress, Flickr while the currently most popular sites Facebook, Twitter, YouTube too were introduced into the empire of Social Media.

It is evident that every year different Social Media sites are added and it is not easy to classify Social Media and provide a suitable definition to differentiate the sites. This research intends to prepare a systematic classification scheme referring the Media Research Theory (Social Presence, Media Richness) and Social Processes Theory (Self Presentation, Self-Disclosure) which are (Kaplan and Haenlein, 2010) the fundamental theories on which the occurrence of Social Media was formulated. The media research theory explains the media aspect of Social Media. This theory highlights the Social Presence and Media Richness subcomponents (Cheety, 2016). Social Presence theory discusses in relation to the level of closeness a person can achieve through technology (Shabbir, Ghazi and Mehmood, 2016). The main influencing factors of Social Presence is considered as the level of intimacy and immediacy of the communication medium. It is clear that an increased social presence can trigger a greater level of social influence on the behavior of communication partners. However, Media Richness theory believes that resolution of vagueness and less uncertainty serve as the main targets of any communication method. This theory states that the most effective communication media has a greater amount of success which is strong in reducing uncertainty. Social Processes theory which discloses the social dimension of Social Media is another fundamental theory of Social Media. Self-Presentation and Self-Disclosure are the two sub-theories within this theory (Cheety, 2016; (Shabbir, Ghazi and Mehmood, 2016). The craving that exists within the people to control the impression that another person form on mind is expressed by Self-Presentation theory. The motive for applying control is to obtain rewards and to form an image, that is reliable with one's uniqueness. Further, Self-Disclosure discusses about exposing personal information intentionally or unintentionally (Shabbir, Ghazi and Mehmood, 2016). This factor is vital in making resilient relationships. More detail analysis of the application of Social Media on Business Performance of tea collectors exposes the prior studies conducted by other authors on this subject in relation to the impact of Social Media Marketing, Social Media effect on Customer Relations and Social Media connection with Information Accessibility on Business Performance (Shabbir, Ghazi and Mehmood, 2016).

\subsubsection{Use of Social Media Marketing}

Creating brand awareness and identification for the brand of the relevant firm is achieved using social media as a tool (Cheety, 2016). Social Media Marketing in the business allows the entrepreneur to bring more people to the website of the business, initiating links to the business website, generating brand awareness, encouraging dialogues about the company contributions and activating discussions about the brand (Weinberg, 2009). This explains as to why Social Media Marketing requires to be given highest priority in order to compete in the current unlimited competition. 


\subsubsection{SocialMedia for Customer Relations}

Nowadays, the product-centric approach which gives attention only to the product characteristics is not encouraged due to the technology-based era (Cheety, 2016). A more customer-centric approach is adhered to focusing on customer experience, ideas, level of satisfaction which are more important for the progress of the organizations. Hence, the Customer Relationship Management (CRM) concept became prominent which promotes business organizations to accomplish a long-term customer relationship in addition to creating a loyal customer base in the current business environment. CRM concept arose with the development of Information Technology. The business field uses the terms of Relationship marketing and CRM interchangeably (Parvatiyar and Sheth, 2001). Adrian Payne and PennieFrow (2006) define CRM as "Strategic approach aimed for creating a better shareholder value by developing suitable relationships with important customers and customer segments". CRM approach allows more opportunities for using information gathered from Social Media, to comprehend the consumer behavior and a solid customer base. The customers consider Social Media sites as service channels, that allows them to an have a consistent real-time relationship with the businesses (Mohammad and Dodokh, 2017). The businesses desire the customers who often check on their Social Media sites for new information about brand offerings and services order to manage a good relationship with the brand. Nevertheless, the managers need to understand that Social Media is capable of making people fall in love with the brand easily and it is also convenient to change that preference to hate it. Hence, it is regarded as a double edge sword to be used carefully (Scott, 2009). Trust is known to be a vital factor for maintaining a cordial relationship with customers (Osterwalder and Pigneur, 2002). Maintaining a good relationship with the customers helps the organization to attract new customers. Therefore, handling customer relations is very important in relation to the progress of the business. However, the businesses confined to traditional marketing approaches and relationship devices, may find it very challenging to maintain an uninterrupted relationship with the customers in competition with the technically strengthened rivals. This is the reason that many businesses create different Social Media sites to be in touch with customer in addition to submitting different services to the customer base.

This study focuses on Customer Relations as a method of creating and improving a solid customer base and brand connections in order to assist the business to understand the market and the behavior of the clients in addition to keeping a good customer network with a reliable customer base. At present as a result of increased Social Media usage, customers expect instant response from the organization to their complaints and demands which necessitates a strong Customer Relationship Management mechanism for the customer satisfaction (Mohammad and Dodokh, 2017). Social Media information sites allow the business to interconnect with their customers. Furthermore, it delivers the customer feedback and follow up discussions regarding the business allows customers to realize the genuine, the organization takes on customer's opinions (Karnegari, Karnam and Shaik, 2013).

\subsubsection{Social Media for Information Accessibility}

Information can be considered as the most valuable resource any organization has access to in today's highly competitive market. Access to information allows a business organization to be more powerful in the market, which is clearly shown by market leaders such as Google. It is very prominent in the world mainly due to their access to information, which permits them to know the customers and market trends. Social Media assists Information accessibility, which supports the organization to recognize customer needs, expedite customer requirements and to provide remedies to the variations of customer sensitivity. The relational information process builds trust and assurance among a business and its clients to be identified as multidimensional concept that comprises capture, access, use, incorporation, and exchange of information (Jayachandran et al., 2005). Unobstructed data movement facility on Social media allows very convenient sharing of information (Meadows-Klue, 2008). Organizations can gain information regarding the customers, competitors, market trends and innovations in the market through Social Media. Further it is possible for the organization to provide details of their products to the customers, introduce new offers, and update on company in addition to improving the information accessibility of the organization (Asian Development Bank, 2005). In the contemporary business field, customers possess easy access to heaps of information and it is essential for a business to stay above all others to win the existing competition in the market (Karnegari, Karnam and Shaik, 2013). CRM can be used as a very productive approach on Social Media. It is necessary for the organizations to have more tools that are accurate in order to use Social Media for CRM. Customers frequently expect the organizations to share extraordinary content in the Social Media sites and updates on the brand. Hence, the organizations need to have a balance between the above purposes and develop an information strategy, which enables to drive the business towards success.

\subsection{Business Performance}

Nowadays, the business organizations concentrate on being dynamic on Social Media networks initiating at least one Social Media site due to popularity of Social Media among consumers. The altered perception of the organizations gave rise to the concept of Social Capital, which values customer relations through the corporate identity and reputation (Paniagua and Sapena, 2014). Business Performance is defined as the procedure of attaining business goals and aims by the conversion of inputs into outputs. Business performance can be the relationship between minimum and effective cost (economy) or the effective cost and realized output (efficiency) as well as the expected output and achieved outcome (effectiveness) (Mohammad and Dodokh, 2017).

There were few theories formulated as business models based on existing best practices identified during the field study in the tea growing areas (Socialbakers, 2016). Three such business models are proposed to overcome the challenges in order to allow the tea industry subsector to progress in the future in Sri Lanka. The striking features of the models are as follows: 


\subsubsection{Supply Chain Model}

The sector displays absence of proper organization in the supply chain of green leaves, shortage of resources for expansion, smallholder indebtedness to leaf collectors, limited cash flow within the supply of green tea leaves and feeling uncertainty among workers (Socialbakers, 2016). A supply chain system to strengthen contractual relationships between farmers and the farmer company, introduce value addition methods for the products and services as well as provision of state support can be proposed to overcome this situation (Mohammad and Dodokh, 2017). This could result in better bargaining position, improved profitability and easy access to capital, relief from smallholder indebtedness to leaf collectors, improved creditworthiness of smallholders and have training and skills development of youth.

\subsubsection{Contract Farming Based Model}

Four stakeholder groups comprising agribusiness firms, farmer collectives, para-state organizations and the financial institutions are brought together in this model. This arrangement tends to formalize the relationships between the key stakeholders and builds a strong para-state body with the participation of key stakeholders to have strong links between stakeholders and to have a regional skilled labor pool (Mohammad and Dodokh, 2017).

\subsubsection{Best Farmer Cluster Model}

This model expects to have a strong and repeated best practice within a particular group of farmers through the best practice farmer playing the role of a "change agent" (Socialbakers, 2016). The expected outcomes of this model are known as enhanced productivity of the farmer group and the improved income for the Tea smallholders and their workers in Sri Lanka

Further, Business performance can be classified as financial and non-financial performance of the organization. Richard et al., (2009) states that business performance is expressed in terms of three dimensions of organizational outcomes. Financial Performance (ROE, ROI, profit, etc.), Product Market Performance (Sales growth, market share, etc.) and Shareholder Return (shareholder return, economic value added, etc.) are the three dimensions. This is a wide concept that incorporates activities of the organization, its products and responsible for their customers. Kaplan and Haenlein, (2010), are of the view that although Social Media offers challenges and opportunities for a business there exists is a noteworthy uncertainty in relation to time, effort and financial budget allocations (Socialbakers, 2016). Deficiency in Social Media awareness results in managers taking decisions without giving due weight to the effect of Social Media on Business Performance. Smart usage of the Social Media sites, enables improved customer communication, attaining customer feedback with immediate response to complaints, expose to increased brand visibility, better customer services, greater access to customer and competitor information, sharing information, and reduction of promotions and managing customer services expenses (Parveen, Jaafar and Ainin, 2016). This research study proposes to measure performance of Green tea leaves collectors through sales, cost reduction and customer satisfaction as financial and non-financial based.

\subsection{Growth}

Social Media provides the advantage of handling a good customer relationship through fulfilling their exact needs. This support earning customer loyalty for the brand creating repeated sales for the business entity. Sales growth is explained as the earnings by the organization from sales during a particular period over and above the value in the former (FarlexInc, 2018). A continuous progress in sales assists the survival of the organization and dynamic with regard to profitability. Promoting the brand and marketing the products through Social Media provides the chance of enhancing sales as well as making profits for the organization. Further, Social Media strengthen developing strategies for organizational processes, forecasting product sales and using the openings offered by the environment (Karnegari, Karnam and Shaik, 2013).

\subsection{Cost Reduction}

The cost reduction in a business is acknowledged as the enduring reduction in per unit cost of production attained without any harm to the existing quality of the product. In contrast to cost savings or cost control, cost reduction results in long-term benefits accomplished by preserving the product quality and elementary features (Mohammad and Dodokh, 2017).

Social Media use in marketing is a cost-effective instrument which decreases the expenses involving marketing, information availability and customer relations activities (Parveen, Jaafar and Ainin, 2016).

\subsection{Customer Satisfaction}

Customer satisfaction is defined by Kotler and Keller (2012) as the feeling of liking or displeasure that arises within a person, as a result of comparing a perceived performance of a product with expectation. The customer is said to be very happy If the organization achieves to surpass the expectations of the customers. Customers evaluate the products purely in relation to the product quality and its capability to fulfill the expectation of the customer as well as the standard of customers loyalty with the brand. Clients show more favorable reaction for the brands they believe to be good (Kotler and Keller, 2012). Therefore, in order to generate more income and achieve sustainable growth, it is essential to understand the customers' needs while maintaining a good relationship

\subsection{Tea Industry in Sri Lanka}

The central and southern provinces of Sri Lanka are responsible for producing most of its tea. The distinctive flavor, color, aroma and seasonality of Ceylon tea is due to the fluctuating elevations and micro-climatic conditions in 
different zones. Sri Lanka has provinces as the first level administrative divisions and Figure 1 shows the tea Growing High-altitude provinces.

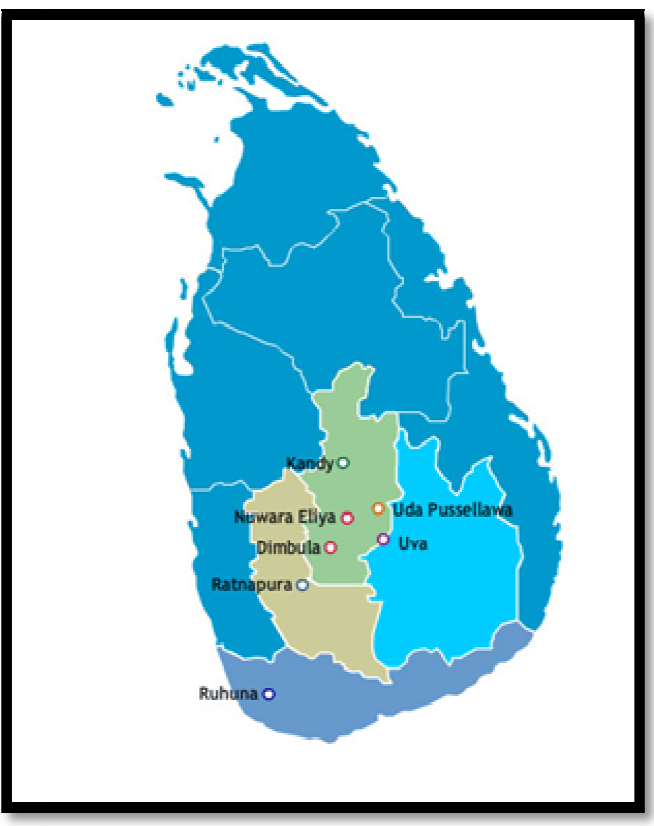

Figure 1: High-altitude Provinces of Tea Growing in Sri Lanka Source: Tea Commissioner's Division - 2014

\subsubsection{Low-country Tea}

Low country tea grown regions exist up to $2000 \mathrm{ft}$ above sea level in Sri Lanka. Long leaf tea is the popular varieties of Ruhuna and Sabaragamuwa regions. The tea from this region offers the beverage with a burgundy hue along with a caramel and malty flavor, when brewed. Middle East, the CIS countries, and the UK have a good demand for this black tea (Sri Lanka Tea Boart, (2015).

\subsubsection{Mid-country Tea}

Mid-country tea growing regions are situated between 2,000ft -4,000ft above sea-level in Sri Lanka. Hilly Kandy area is well known for tea with its full-bodied flavor and a copper tint, which is a favorite among the Australians and Americans.

\subsubsection{High-country Tea}

High country tea grown areas are located above 4,000ft from sea-level in Sri Lanka. The tea from eastern highlands of Uva, is renowned world-wide for its powerful and refreshing smell. The micro-climatic conditions exclusive to Uva allows land owners to trial in growing new types of tea. The other high-altitude provinces popular for growing tea in Sri Lanka are Nuwara Eliya, Dimbula, and Uda Pussellawa(Sri Lanka Tea Boart, (2015).

There are six main tea producing areas in Sri Lanka Tea Commissioner's Division - 2014. Galle situated in south of the island, Ratnapura, around $65 \mathrm{Km}$ east from Colombo, Kandy, in the middle of the country, Nuwaraeliya in the highlands, Dimbula, towards west of the central mountains, and Uva located east of Dimbula. From among these areas Galle area was selected for this research study.

The number of tea holdings by provinces in Sri Lanka is illustrated in the table 1.

\begin{tabular}{|c|c|}
\hline Province & No. of Tea Holdings \\
\hline Western & 8,525 \\
\hline Central & 26,000 \\
\hline Southern & 101,818 \\
\hline North Western & 135 \\
\hline Uva & 15,440 \\
\hline Sabaragamuwa & 55,138 \\
\hline
\end{tabular}

Table 1: Number of Tea Holders by Provinces in Sri Lanka Source: Tea Commissioner's Division - 2014

\subsubsection{Green Tea Leaves Collectors}

Tea producing system involves the main activity of collecting the green tea leaves by the collectors in the area. The tea industry consists of two main subsectors which are the large plantation companies known as corporate subsector and tea smallholdings. Over 70 per cent of green leaf requirement is produced and supplied by the Smallholder farmers before these are processed in the tea factory to be transformed into "made tea". The collectors of green tea leaves assist the smallholdings to enhance their progress (Tea Commissioner's Division - 2014). 


\subsection{Collection Systems for Green Leaves}

All the personnel and establishments starting from the producers up to users are included in the collection systems of green leaves. The smallholders are identified as producers while the users are known to be the private individuals who own tea processing factories. Generally, smallholders are classified as the holdings having less than 10 acres (4 ha). However, there are lands classified as smallholdings which exceed 10 acres, but the majority of the smallholdings (around 88 per cent) tend to be lesser than half (1/2) ha (Sri Lanka Tea Boart, 2015).

The green leaf collectors occupy the middle position in the supply chain of green tea leaves. It is evident that leaf collectors deal with majority of green leaves. Leaf collectors serve as the individual dealers by being an intermediate in moving the green leaf from smallholder to the factory thus making an income. Since the smallholder subsector is less organized and yield is sold in an imperfect market, the dealers play a prominent role in the supply chain (Daily News, 2007). The leaf collectors gather green leaves from the smallholders into woven poly propylene (WPP) sacks or plastic crates kept in lorries driven through the villages (Sri Lanka Tea Boart, 2015). This is an entangled network of a supply as majority of smallholders provide more than one collector. These green tea leaves are then collected at a common place run by each collector and re-packed to form a fewer number of tightly packed sacks weighing approximately $20 \mathrm{~kg}$ each. Basic Structure of the Tea Industry in Sri Lanka presented in the figure 2.

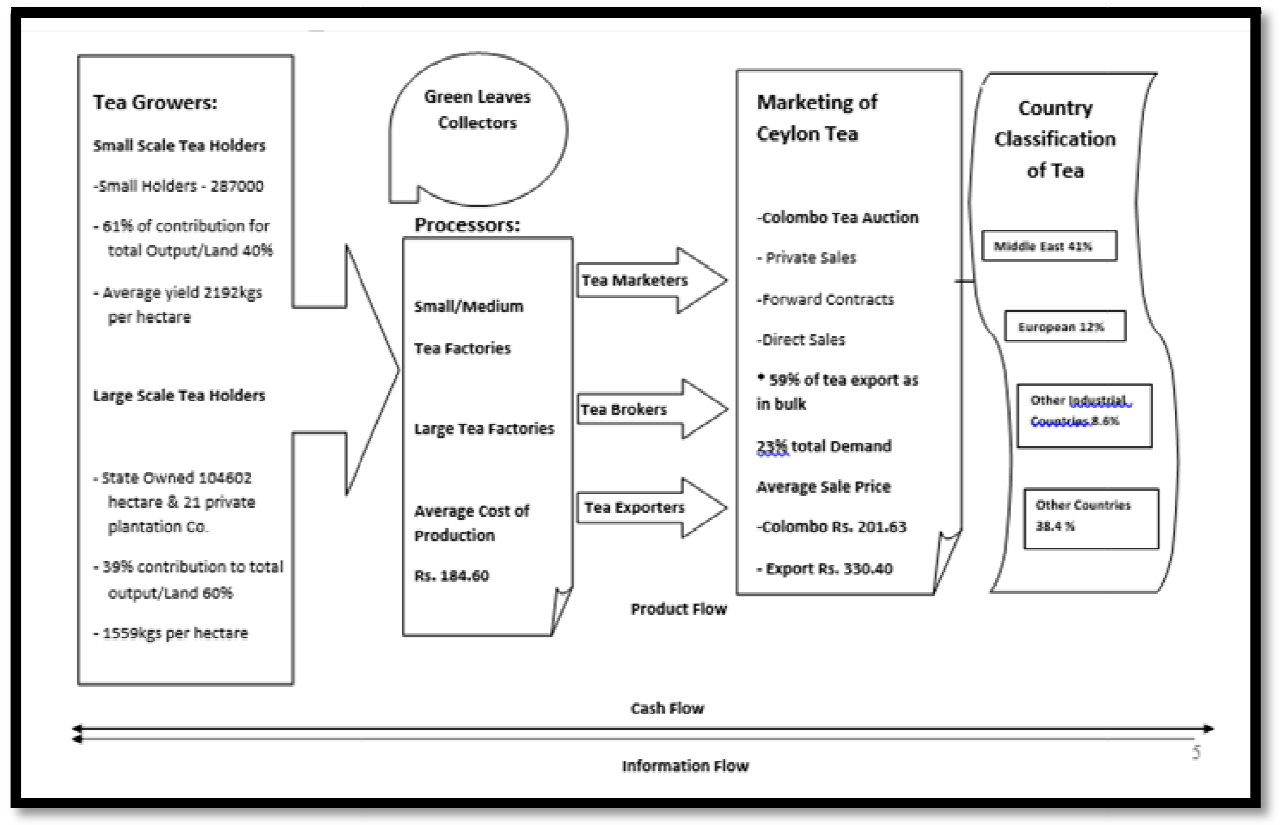

Figure 2: Basic Structure of the Tea Industry in Sri Lanka Source: Gamage and Wickramasinghe, 2000

It is clear that Tea Smallholder sector in Sri Lanka has strong economic and social relationships between the smallholder farmers and leaf collectors (Daily News, 2007). Some leaf collectors exposed that few millions of rupees have been involved in transactions with smallholders as advances paid for the supply of green leaves, and as credit and assistance in cash or in kind during tough times faced by the farmers. This, situation pushes the farmers into indebtedness. Farmers themselves from the smallholdings to factories as well as factory transport (collecting) agents deliver a reasonable amount of green leaves. Farmers deliver green leaves generally to the small-scale factories, and the RPCs get a fewer amount of yield through their collectors who are paid for this conveyance in the supply chain. The societies that are confined and limited to tea inspector areas have membership that varies between 400 and 500. Any tea smallholder has the eligibility to be a member of the smallholder society. The office bearers of the smallholder societies hire lorries and people to gather green leaves from their members in order to transport these to the factory. Further, non-members take undue advantage of this service as they too could supply to the society at the same price. But this issue has not created a major problem yet. The overall quality of the tea depends on the superiority of the green leaves, which is a vital factor. The smallholders have not yet been able to produce high quality tea, regardless of having an excellent knowledge on issues pertaining to the quality of green leaves. No stakeholders are working towards high quality tea, but it is limited to tea factories. The factory officers revealed that they are engaged in a tough competition to obtain green leaves to ensure continuous production of made tea by running the working shifts. Leaf collectors exposed that their job in the supply chain too is very competitive while the quality of green leaves very often gets negotiated to have a regular supply of green leaves from the smallholders. There is no value addition-taking place within the supply chain concerning the leaf collectors. However, in the Ratnapura district, particular smallholders and factories of the RPCs are involved in a certification scheme with the RA for sustainable tea cultivations, which is an exception to the normal situation. RPCs are offered premium prices for made tea the and certified smallholders get it for green leaves. The system of RA Certified Smallholders and Collectors are presented in figure 3. 


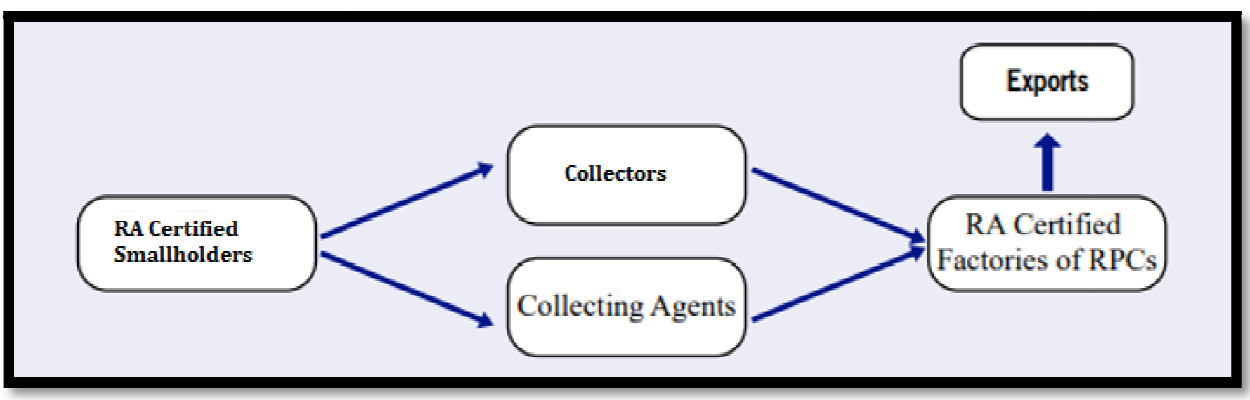

Figure 3: RA Certified Smallholders Collectors

Source: ILO, 2015

During visits to collectors' locations, it was revealed that most of the collectors were carrying out successful operations. Majority had good recording systems while some even computerized the information. Further, most of the collectors have taken steps to involve the next generation in their business. Many of them showed signs of lucrative livelihoods as a result of the income from this business (Asian Development Bank, 2005; ILO, 2015).

\section{Methodology}

In a study, Social Media is considered as the independent variable and Business Performance of Green tea leaves collectors are selected as the dependent variable. After a detailed review of the literature, the methodology was designed. Social Media Marketing and Accessibility to Customer Relations as well as Information, have been identified as the most significant elements in the concept of Social Media, accordance with the literature. These three variables were adopted from research studies conducted by Parveen, Jaafar and Ainin (2016), Teo and Choo (2001) and Mohammad and Dodokh (2017). All these authors studied the effects of Social Media on business performance using the above variables in their relevant fields and situations. Figure 4 illustrates, the research conceptual model used for the study in relation to the above variables and dimensions.

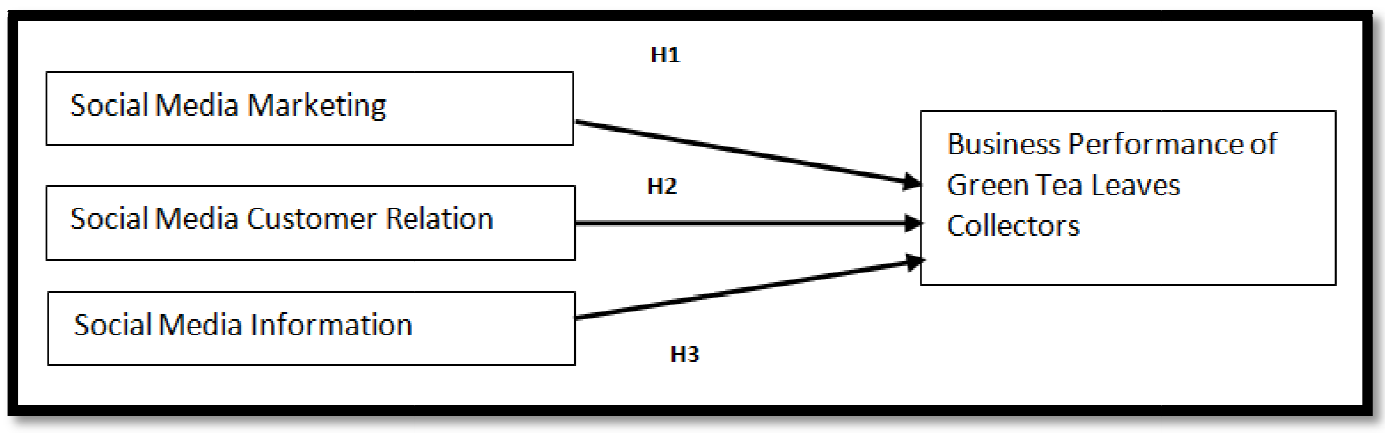

Figure 4: Conceptual Framework

Sales Growth, Cost Reduction and Customer Satisfaction are the components of the dependent variable. Sales Growth dimension was adopted from the study Bhanot (no date) and Aliu and Halili (2013) while studies done by Fernando et al. (2017), Parveen, Jaafar and Ainin (2016) and Mohammad and Dodokh (2017) supported to select Cost Reduction and Customer Satisfaction.

Both primary and secondary data have been scrutinized in the study in order to achieve the study objectives. The site Social bakers offer information with respect to relevant geographical location and the business. The web content analysis method was applied to identify the green tea leaves collectors who use Social Media. Organization sites were browsed using this technique, to detect the green tea leaves collectors active in Social Media. Approximately 272 the green tea leaves collectors were found (Socialbakers, 2016) through above-mentioned Social Media sites. Therefore, 272 was considered as the sampling frame, but selected green tea leaves collectors for this study was only160. The response rate is recorded to be 97 percent in this study.

The questionnaire of the study was tested as Pre-Test and Pilot Test before the collection of final data as a measure of accuracy. The level of the reliability and validity of the questionnaire was checked by these tests to decide the ability of generating the intended accurate results through the developed questionnaire. Reliability was recorded as 0.766 for Social Media and 0.774 for Business Performance during the Pilot Study. The content validity of the questionnaire was measured based on the relevant literature of the study during the Pilot Test. The questionnaire was validated as the instrument indicated true statements based on the literature.

\section{Data Analysis}

The results of the collected data, were analyzed using Smart PLS (Partial Least Square) which is a computerized program designed for simple and complex data management and analyses., Reports, graphs, and comparisons were generated by this analysis on the aggregate of data gathered from the respondents. It is essential for the data to be accurate and complete enabling arrangement in a format to apply several SEM concepts for explanation. 
Reliability of the measurement instrument is indicated by consistency. The level of motivation on the part of the participant should be the same when a response is given in completing a questionnaire, anytime the test is performed. The results obtained for reliability of the study are presented in the table 2.

\begin{tabular}{|l|l|}
\hline \multicolumn{1}{|c|}{ Items } & \multicolumn{1}{|c|}{$\begin{array}{c}\text { Cronbach's } \\
\text { Alpha }\end{array}$} \\
\hline Social Media Marketing (SMM1 - SMM6) & 0.837 \\
\hline Customer Relations (SCR1 - SCR6) & 0.817 \\
\hline Information Accessibility (SIA1 - SIA6) & 0.852 \\
\hline Business Performance (BSG, BCR, BCS) & 0.832 \\
\hline
\end{tabular}

Table 2: Reliability Results of the Study

A Cronbach's Alpha was used in testing Reliability of the questionnaire and all dimensions showed values greater than 0.7. With a view to identify the structure of the data set having multiple variables, the Exploratory Factor Analysis (EFA) was used (Statistics Solutions, 2017a). A fundamental assumption used in EFA is that each indicator has the option of being linked with any relevant factor. The value of total variance needs to be greater than fifty percent.

The Structural Equation Model (SEM) evaluates the structural relationships as a multivariate statistical analysis technique. SEM analyses the connection between variables and latent constructs by combining the factor analysis and multiple regression analysis (Statistics Solutions, 2017b).

The collinearity among the variables could be rejected if the VIF value is less than 5. Since VIF values of all three independent variables are less than 5 Collinearity issue does not arise among the variables.

All the exogenous constructs of the study indicate positive path coefficient values. The highest path value among all variables is shown by Social Media Customer Relation (CSR) depicting a high level of significance than the other variables. However, a relatively lower level of path coefficient was indicated by Social Media Marketing (SMM) depicting a weaker association with Total Business Performance. All other variables reveal a significant value of 0.001 which means that the path coefficient values of the variables SCR and SIA are significant with t-test values of 3.613 and 3.813 respectively. As the analysis criterion suggests the SMM variable was removed from the study since the T Statistics value of the variable is insignificant.

A value of 0.552 was shown by the Coefficient of Determination which predicts that the independent/exogenous variable explains 55.2 percent of the variation in the dependent/endogenous variable.

\section{Discussion}

All business organizations in the country face the challenge of survival in the current business environment (Jaafar and Ainin, 2016; Teo and Choo, 2001). The development of technology is regarded as the major reason of the change in the business system (Asian Development Bank, 2005). Organizations interested in becoming a success are forced to handle the transformation in the business environment to achieve their place in the market while attaining sustainable growth (Lawson and Price, 2003).

Social Media can be treated as a device that allows not only communication but useful for promotion and marketing activities. An increase in the performance of the local SMEs has been observed through active engagement in Social Media by eliminating cross-border trading barriers (Jaafar and Ainin, 2016; Teo and Choo, 2001). This research study concentrates on the tea sector in the Pitigala area in Galle District of Sri Lanka to study the link between Social Media and Business Performance of green tea leaves collectors.

Conventionally the internet was used only to read content and trading purposes. However, today it has become an important part of our daily life and Social Media is no longer a want, it is a need. Based on the Social Media phenomenon various portals have been established for the creation and sharing internet information. Social Media with the outstanding fluctuations in the business environment, has succeeded in grabbing the marketing and advertising channels that were conspicuous in the recent past (Jaafar and Ainin, 2016; Teo and Choo, 2001; Mohammad and Dodokh, 2017). Businesses cannot neglect the consequence of using social media for business activities, especially in the world of marketing, when such an infiltration takes place. The effect of Social Media on Business Performance of Green tea leaves collectors, is the study intends to provide extensions to the previous studies on this subject by other authors, highlighting on the effect of Social Media Marketing (Jaafar and Ainin, 2016; Teo and Choo, 2001), Social Media for Customer Relations and Social Media for Information Accessibility on Business Performance. The research study pursues to assess the affiliation between Social Media and Business Performance of green tea leaves collectors at the Pitigala area in Galle district of Sri Lanka. Literature reveals that Social Media Marketing, Customer Relations and Information Accessibility are the most influential elements recognized within the concept of Social Media. These variables were adopted from the research studies of Jaafarand Ainin (2016), Teo and Choo (2001) and Mohammad and Dodokh (2017) who have used these to examine the effect of Social Media on business performance in their respective areas and background.

The study sampling framework is 272 Green tea leaves collectors. The sample size was taken as 160 Green tea leaves collectors in the selected area as the size of the sample was identified as justifiable based on the book on Research 
Methods for Business: A Skill Building Approach (Sekaran and Bougie, 2013) in which the author outlines a table to find the sample size as per the given population.

\section{Implications of the Study}

The results of the study reveal that Social Media has a positive impact on Business Performance if used in business activities. Both Social Media indicated a strong relationship for Customer Relations and Information Accessibility with Business Performance. Few deficiencies in this research study led to areas for future research. Use of in-depth interviews in addition to questionnaires could deliver more profound and wider set of information on the impact of Social Media on Business Performance. This could increase the validity and reliability of the findings while decreasing the degree of biasness.

\section{Recommendation}

These recommendations are inclined to enhance the sustainability and productivity of the tea smallholder subsector while creating and keeping decent work within the framework of numerous changes taking place in the world of work. It is appropriate to use information and communication technology to modernize the supply chain operations by associating the phenomenon of social media for the entire tea industry.

This research study anticipated to fill the gap in knowledge relating to how and to what extent the Social Media usage could improve the performance of green tea leaves collectors at Pitigala area in Galle District of Sri Lanka. The foremost objective of the study was providing awareness to the academia, entrepreneurs and policymakers in relation to progress of Green tea leaves collectors sector in the country while leading Sri Lanka towards prosperity and sustainable growth.

\section{References}

i. Aliu, A. and Halili, A. (2013). The Impact of Information and Communication Technologies as a Tool to Facilitate Growth in the Manufacturing Sector in Republic of Kosovo", Procedia Technology. Elsevier B.V., 8(Haicta), pp. 465-470. doi: 10.1016/j.protcy.2013.11.060.

ii. Asian Development Bank (2005). 'Report and Documentation of the President to the Board of Directors on a Proposed Loan and Technical Assistant Grant to the Democratic Republic of Sri Lanka for the Plantation Reform Project'.

iii. Asur, S. et al. (2011),,Trends in Social Media : Persistence and Decay". doi: -

iv. Chetty, P. (2016),Importance of research approach in a research / Knowledge Tank. Available at: https://www.projectguru.in/publications/selectingresearch-approach-business-stud.

v. Daily News (2007),Tea-Lanka's second largest foreign exchange earner.Daily News. Thursday, 29 August.

vi. Edosomwan, S. et al. (2011)„The History of Social Media and its Impact on Business", Management, 16(3), pp. 7991. Available at: http://search.proquest.com.eproxy.ucd.ie/docview/889143980

vii. FarlexInc (2018),Sales Growth financial definition of Sales Growth. Available at: https://financialdictionary.thefreedictionary.com/Sales+Growth (Accessed: 3 September 2018)

viii. Fernando, V. et al. (2017),, The impact of green attributes on customer Loyalty of supermarket outlets in Sri Lanka", 3rd International Moratuwa Engineering Research Conference, MERCon 2017, (October), pp. 395-400. doi: 10.1109/MERCon.2017.7980517.

ix. Jayachandran, S. et al. (2005),The Role of Relational Information Processes and Technology Use in Customer Relationship Management", Journal of Marketing, 69(4), pp. 177-192. doi: 10.1509/jmkg.2005.69.4.177.

X. Kaplan, A. M. and Haenlein, M. (2010),Users of the world, unite! The challenges and opportunities of Social Media", Business Horizons, 53(1), pp. 59-68. doi: 10.1016/j.bushor.2009.09.003.

xi. Karnegari, K. R., Karnam, V. S. and Shaik, G. (2013), An Analysis of Business through Social Media"

xii. Kotler, P. and Keller, K. L. (2012) „Marketing Management. 14th edn. One Lake Street, Upper Saddle River,New Jersey 07458: Prentice Hall PTR.

xiii. McFadden, C. (2017). A Chronological History of Social Media, Interestingengineering.Com. Available at: https://interestingengineering.com/chronological-history-of-social-media (Accessed: 27 August 2018).

xiv. Meadows-Klue, D. (2008), Opinion Piece: Falling in Love 2.0: Relationship marketing for the Facebook generation", Journal of Direct, Data and Digital Marketing Practice, 9(3), pp. 245-250. doi: 10.1057 /palgrave.dddmp.4350103.

xv. Mohammad, A. and Dodokh, I. (2017) The Impact of Social Media Usage on Organizational Performance: A Field

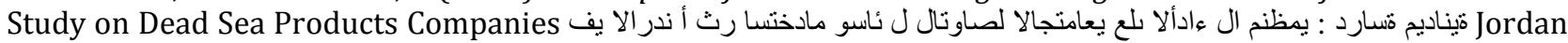
in .تيمال رحبال تاجنتم تاكرش لـع

xvi. Osterwalder, A. and Pigneur, Y. (2002). An e-business model ontology for modeling e-business", 15th Bled Electronic Commerce Conference, June 17, 19, p. 12. doi: 10.1.1.16.633.

xvii. Paniagua, J. and Sapena, J. (2014)„Business performance and social media: Love or hate?", Business Horizons. Elsevier, 57(6), pp. 719-728. doi: 10.1016/j.bushor.2014.07.005.

xviii. Parvatiyar, A. and Sheth, J. N. (2001)„Customer Relationship Management: Emerging Practice, Process and Discipline", Journal of Economic $\{\&\}$ Social Research, 3(2), pp. 1-34.

xix. Parveen, F., Jaafar, N. I. and Ainin, S. (2016),SSocial Media's impact on organizational performance and entrepreneurial orientation in organizations", Management Decision, 54(9), pp. 2208-2234. doi: 10.1108/MD08-2015-0336. 
xx. Scott, D. M. (2009)„,World Wide Rave: Creating Triggers that Get Millions of People to Spread Your Ideas and ShareYour Stories. Available at: http://books.google.es/books?id=oGNGODF_XDgC.

xxi. Shabbir, M. S., Ghazi, M. S. and Mehmood, A. R. (2016)„, Impact of Social Media Applications on Small Business Entrepreneurs", Management and Economics Research Journal, 2(3), p. 1. doi: 10.18639/MERJ.2015.02.200914.

xxii. Shaw Atanu (2018),,How Social Media Can Move Your Business Forward. Available at: https://www.forbes.com/sites/forbescommunicationscouncil/2018/05/11/howsocial-media-can-move-yourbusiness-forward/\#34ba32bc4cf2 (Accessed: 22 August 2018).

xxiii. Socialbakers (2016)„,Definitive portal for social media statistics globally", Socialbakers.com. doi: 10.1144/GSL.SP.1991.058.01.10.

xxiv. Sri Lanka Tea Boart, (2015), Library Collections Colombo

xxv. Statistics Solutions (2017a),Exploratory Factor Analysis - Statistics Solutions. Available at: https://www.statisticssolutions.com/exploratory-factor-analysis/ (Accessed: 3 November).

xxvi. Statistics Solutions (2017b),,Structural Equation Modeling - Statistics Solutions. Available at: https://www.statisticssolutions.com/structuralequation-modeling/ (Accessed).

xxvii. Stockdale, R. and Ahmed, A. (2012),Identifying Business Value From The Use Of Social Media: An SME Perspective".

xxviii. Teo, T. S. and Choo, W. Y. (2001),Assessing the impact of using the Internet for competitive intelligence", Information \& Management, 39(1), pp. 67-83. doi: 10.1016/S0378-7206(01)00080-5.

xxix. Weinberg, T. (2009)The New Community Rules: Marketing on the Social Web. O"Reilly Media; 1 edition (July 17, 2009). 